ORIGINAL ARTICLE

\title{
Antibiotic Resistance Patterns of Common Gram-negative Uropathogens in St. Paul's Hospital Millennium Medical College
}

\author{
Yeshwondm Mamuye ${ }^{1}$
}

\begin{abstract}
BACKGROUND: The resistance of bacteria causing urinary tract infection (UTI) to commonly prescribed antibiotics is increasing both in developing and developed countries. Resistance has emerged even to more potent antimicrobial agents. This study was undertaken to determine the current antibiotic resistance pattern among common bacterial uropathogens in St.paul's Hospital Millennium Medical College.

METHODS: Using cross sectional study design, a total of 217 female and 207 male participants were consecutively recruited. Mid-urine samples were collected from all patients using wide mouthed urine cup. Inoculation was performed onto blood agar and MacConkey agar symoultaniously, and isolated organisms were identified by conventional methods. Antibiotic susceptibility was done by Kirby Bauer disk diffusion method. Thirteen different antibiotics representing different families of antibiotics were tested on all isolated organisms.

RESULT: Of the total 424 samples, 95(22.4\%) showed significant growth. Gram negative organisms totaled $85(20.05 \%)$, and $10(2.4 \%)$ isolates were gram positive. The most frequently isolated gram negative bacterium was E. coli followed by Protues and Klebsiella spp. 53(12.5\%), 8(8.4\%), and 7(7.4\%) respectively. Resistance to Tetracyclin, Ampicilin, Amoxycilin and Nalidixic Acid was more than $70 \%$ of all isolates of E.coli strains. There was relatively low resistance rate to Nitrofurantoin, Gentamycin and Trimethoprim-Sulfamethoxazole. However, there was emerging resistance to Ciprofloxacilin and Ceftriaxone especially for common bacteruria.

CONCLUSIONS: In this study setting, resistant rates to Tetracyclin, Ampicilin, Amoxycilin and Nalidixic Acid were high. Since most isolates were sensitive for Nitrofurantoin, Gentamycin and Trimethoprim-Sulfamethoxazole, they are considered as appropriate antimicrobials for empirical treatment for urinary tract infections with the absence of culture and sensitivity setting. Increasing antibiotic resistance trends indicate that it is imperative to rationalize the use of antimicrobials in the community and use these conservatively.

KEYWORDS: Antibiotic Resistance, Uropathogen, Addis Ababa, Ethiopia
\end{abstract}

DOI: http://dx.doi.org/10.4314/ejhs.v26i2.2

\section{INTRODUCTION}

Urinary tract infection (UTI) is a term applied to a variety of clinical conditions ranging from asymptomatic presence of bacteria in the urine to sever form of the kidney with sepsis (1). UTIs are one of the most common bacterial infections in humans both in the community and hospital settings (2). Worldwide, approximately 150 million people are diagnosed with UTIs resulting in 6 billion USD health care expenditures (1). UTIs are the most common bacterial infections encountered by clinicians in developing countries (3).

Most UTIs are caused by Gram-negative bacteria like Escherichia coli (E. coli), Klebsiella spp., Proteus mirabilis, Pseudomonas aeruginosa, Acinetobacter spp., and Serratia spp. and Gram-

\footnotetext{
${ }^{1}$ Department of Microbiology St. Paul's Hospital Millennium Medical College, Addis Ababa, Ethiopia Corresponding Author: Yeshwondm Mamuye, Email: y_mamuye@yahoo.com
} 
positive bacteria such as Enterococcus spp. and Staphylococcus spp.(4). The commonest bacterial agent involved in causation of UTIs is Escherichia coli, the principal pathogen both in the community as well as in the hospital (5).

The treatment of UTIs varies according to age, sex, underlying disease, infecting agent and involvement of lower or upper urinary tract. According to the Infectious Diseases Society of America (IDSA) guidelines, the recommended drug is Trimethoprim/sulphamethoxazole for the treatment of UTIs in settings where the prevalence of resistance is $<10-20$ percent and ciprofloxacin is recommended where this resistance is $>20$ percent (6). The other agents used in the treatment of UTI include fluoroquinolones, cephalosporins and other $\beta$-lactams with or without $\beta$-lactamase inhibitors and nitrofurantoin (7).

Drug resistance among bacteria causing UTI has increased since introduction to UTI chemotherapy (8). The etiological agents and their susceptibility patterns of UTI vary in regions and geographical locations. Besides, the etiology and drug resistance change through time (9). Knowledge of the local bacterial etiology and susceptibility patterns is required to trace any change that might have occurred in time so that They can give updated recommendation for optimal empirical therapy of UTI (10). In Ethiopia, a number of studies have been done on the prevalence and antimicrobial resistance patterns of UTIs $(4,11-$ 13). However, as the pattern of bacterial resistance is constantly changing, monitoring antimicrobial susceptibilities is important. It provides information on the pathogenic organisms isolated from patients, and assists in choosing the most appropriate empirical antimicrobial therapy. In addition, continuous surveys of antimicrobial resistance are crucial for monitoring changes in this resistance. The aim of this study was therefore to determine the resistance patterns of gram negative isolates from suspected UTI for the most commonly used antimicrobials.

\section{MATERIALS AND METHODS}

A cross sectional study was conducted in St.Paul's Hospital Millennium Medical College (SPHMMC), Addis Ababa, Ethiopia. It is an urban setting and tertiary hospital for Ethiopian and teaching hospital for national and international students. The hospital provides out- and in-patient services with 370 beds. Accordingly, patients being seen at SPHMMC come from all over the Northern, Western, Southern and Eastern parts of Ethiopia. However, most patients seeking medication at SPHMMC are predominantly from Northern Oromia Regional State and Addis Ababa city administrations.

Sample Size Calculation and Sampling Technique: The sample size for the study was calculated using the formula $(n=(z \alpha / 2) 2 p(1-p) /$ d2) for estimating a single population proportion at $95 \%$ confidence interval $(\mathrm{CI})(\mathrm{Z} \alpha / 2=1.96), 5 \%$ margin of error, and $10 \%$ non-respondence rate by taking $50 \%$ prevalence since there is no current study in the setting. Therefore, the total sample size for this survey was 424 . However, a total of 200 pregnant women were consecutively selected to increase the finding or detection rates of cytomegalovirus infection rate in the study settings.

Data Collection and Sampling Procedure: Age and sex have been taken from patients' request forms. A total of 424 participants suspected for UTI were recruited using consecutive sampling techniques. Clean catch mid-stream urine samples were collected using sterile wide mouth container from enrolled patients. The minimum acceptable volume of urine sample was $10 \mathrm{ml}$. All the samples were analyzed immediately after arrival to the laboratory to ensure that the pathogenic organisms present in the urine are isolated and to avoid over population of the pathogenic organism.

Culture and Identification\{ Urine specimens were directly inoculated onto blood agar (Oxoid, England) and MacConkey agar (BD, USA) using a sterile standard calibrated wire loop (0.001), and streaked culture plates were incubated at $37^{\circ} \mathrm{C}$ aerobically for $24 \mathrm{hrs}$. Number and type of colony count was done on blood agar plate, and then significant bacteriuia was determined. Cultures with colony counts greater than $10^{5} \mathrm{cfu} / \mathrm{ml}$, for a single isolated bacteria was consider significant. Identification of bacterial isolates was done using colony characteristics on blood agar, MacConkey agar and gram reaction of the bacteria and biochemical tests in accordance with standard procedures.

Organisms isolated from urine specimens of hospitalized and outpatients over a six month period (August 2013 to January 2014) were 


\begin{abstract}
identified and tested for antimicrobial susceptibilities. In this study, only samples with significant growth were studied (significant growth was defined as the presence of $>10^{5}$ colony-forming units per milliliter $(\mathrm{cfu} / \mathrm{mL})$ of urine (14). After obtaining the pure strains, the strains were subjected to conventional biochemical identification methods to identify different gram-negative uropathognes.
\end{abstract}

Antimicrobial Susceptibility Tests: According to the standard operational procedures, antimicrobial susceptibility tests were done on Mueller-Hinton agar (Oxoid, England) using Kirby-Bauer disk diffusion method (15). Briefly, using a sterile wire loop, 3-5 pure colonies were picked from blood agar plate or MacConkey agar and emulsified in nutrient broth (Oxoid, England) and mixed gently until it formed a homogenous suspension. The turbidity of the suspension was then adjusted to the optical density of McFarland 0.5 tubes in order to standardize the inoculums size. A sterile cotton swab was then dipped into the suspension and distributed the bacteria suspension evenly over the entire surface of Mueller-Hinton agar (Oxoid, England). The antimicrobial agents tested were: Ampicillin (Amp), Amoxycillin (10 $\mu \mathrm{g})$, Chloramphenicol $(30 \mu \mathrm{g})$, Nalidixic Acid (NA), Nitrofurantoin $(300 \mu \mathrm{g})$, Gentamicin $(10 \mu \mathrm{g})$, Ciprofloxacillin $(5 \mu \mathrm{g})$, Cephalothin $(30 \mu \mathrm{g})$, Ceftriaxone (30 $\mu \mathrm{g})$, Norfloxacin (NOR), Doxycycline $\quad(30 \mu \mathrm{g}), \quad$ TrimethoprimSulfamethoxazole $(25 \mu \mathrm{g})$, and Tetracycline (30 $\mu \mathrm{g})$. Resistance data were interpreted according to Clinical Laboratory Standards Institute. Reference strains of E. coli ATCC 25922 and Staphylococcus aureus ATCC 25923 (S. aureus) were used for quality control for antimicrobial susceptibility (16).
Data Analysis: The data was entered and analyzed using SPSS statistical software package (version 20). The descriptive statistics and proportion of the findings in relation with age and sex were computed by percentages.

Ethical Clearance: Ethical approval was obtained from St. Paul's Hospital Millennium Medical College Institutional Review Board (IRB). Letter of permission was also obtained from St.paul's Hospital Millennium Medical College. Written and informed verbal consent was taken from study participants after clear explanations about the purpose and aims of the project were given. The study participants were given verbal assurance for the confidentiality of their responses. Based on the findings the results were communicated to clinicians.

\section{RESULTS}

A total of 424 [217(51.2\%) female and 207 (48.8\%) male] participants were enrolled. The age range of the participants was 1-78 years, with mean age of $32.8 \pm 17.9$ years. Thirty five of them were under twenty, $62.5 \%$ between $20-35$ and $29.2 \%$ were above 36 years (Table 1 ).

In August 2013 to January 2014, a total of 424 urine specimens were examined for isolations and identifications of bacteria and susceptibility testing. Of these, 95(22.4\%) urine samples showed significant bacterial growth, with 32/262 (12.2\%), and $63 / 162(38.9 \%)$ were pointed out for asymptomatic and symptomatic UTI patients respectively. The proportions of isolates were gram negative $85(20.05 \%)$, and $10(2.4 \%)$ gram positive.

Table 1: Age and sex distribution of patients with suspected UTI in St.Paul's Hospital Millennium Medical College, Addis Ababa, Ethiopia, 2013/2014.

\begin{tabular}{lllll}
\hline Variables & Category & Total (N/\%) & Positive (N/\%) & Negative (N/\%) \\
\hline Sex & Female & $217(51.2)$ & $56(25.8)$ & $161(74.2)$ \\
& Male & $207(48.8)$ & $41(19.8)$ & $166(80.2)$ \\
Age group & $\leq 20$ & $35(8.3)$ & $12(34.3)$ & $23(65.7)$ \\
& $20-35$ & $265(62.5)$ & $49(18.5)$ & $216(81.5)$ \\
& +36 & $124(29.2)$ & $44(35.5)$ & $80(64.5)$ \\
\hline
\end{tabular}


Species of the bacteria were: E. coli 53(55.8\%), Proteus spp. 8(8.4\%), Klebsiella spp. 7(7.4\%), Enterobacter spp. 6(6.3\%), Citrobacter spp. 5(5.3\%), Providenicia spp. 3(3.2\%) and Pseudomonas spp. 3(3.2\%). Among the gramnegative, $E$. coli was the most frequently isolated organism (62.4\%) followed by Proteus spp. (9.4\%) and Klebsiella spp. (8.2\%) (Table 2). Resistance to DO, TE, Amp, Aml and NA was observed in $71.7,83.0,79.2,75.5$, and $73.6 \%$ of the $E$.coli isolates respectively. Low resistance SXT, F and CN rate was observed in 22.6, 20.8, and $22.6 \%$ respectively (Table 3 ).

Fifty-four per cent of all E.coli isolates were found to be resistant to ciprofloxacin. Ciprofloxacin resistance was comparatively less among the other Gram-negative uropathogens like Proteus spp and Entrobacter spp, but higher in
Klebsiella spp as mentioned (Table 1). Resistance to the gentamicin was also considerable especially among isolates of Citrobacter spp and Entrobacter spp with as many as 60.0, and 50.0 per cent of all isolates showing resistance to gentamicin respectively (Table 3 ).

The rates of resistance among Gram-negative uropathogens to third generation cephalosporins like ceftriaxone were high. Ceftriaxone resistances were seen in 45.3 and 71.4 percent of all isolates of E. coli and Klebsilla spp respectively (Table 3).

In this study, the overall resistance rates to two and more antimicrobials was $77.6 \%$, and only $4(4.7 \%)$ were sensitive to all antimicrobials tested. The resistances to two and more antimicrobial agents were $100.0 \%, 81.2 \%, 85.8 \%$ and $100.0 \%$ to Entrobacter spp., E. coli, Klebsiella, and Pseudomonas respectively (Table 4).

Table 2: Frequency of isolated species among a study $(n=424)$ participants in St.Paul's Hospital Millennium Medical College, Addis Ababa, Ethiopia, 2013/2014

\begin{tabular}{llll}
\hline Bacterial Isolates n(\%) & & Frequency & Percent \\
\hline \multirow{2}{*}{ Gram - positive 10(2.4) } & S.aurues & 5 & 5.3 \\
& S.saprofiticus & 3 & 3.2 \\
& S.epidermides & 2 & 2.1 \\
& E.coli spp. & 53 & 55.8 \\
& Proteus spp. & 8 & 8.4 \\
Gram - negative 85 (20.05) & Klebsiella spp. & 7 & 7.4 \\
& Enterobacter & 6 & 6.3 \\
& spp. & & 5.3 \\
& Citrobacter spp. & 5 & 3.1 \\
& Providenicia & 3 & 3.1 \\
\hline & spp. & & \\
& Non-Fermenter & 3 & \\
\hline
\end{tabular}

Note: S.aureus $=$ staph auereus, E.coli $=$ Ectieritia coli 
Table 3: Antimicrobial susceptibility of bacterial isolates from patients with suspected UTI at St.Paul's Hospital Millennium Medical College, Addis Ababa, Ethiopia 2013/2014.

\begin{tabular}{lllllllllllllll}
\hline Bacteria & No.isolates & Amp & C & Aml & SXT & CIP & CRO & F & CN & NA & KF & NOR & DO & TE \\
\hline E.coli Spp. & 53 & 79.2 & 30.2 & 75.5 & 22.6 & 54.7 & 45.3 & 20.8 & 22.6 & 73.6 & 32.1 & 67.9 & 71.7 & 83.0 \\
Proteus spp. & 8 & 62.5 & 37.5 & 62.5 & 3.8 & 12.5 & 0 & 37.5 & 25.0 & 50.0 & 62.5 & 12.5 & 50.0 & 62.5 \\
Klebsiella spp. & 7 & 85.7 & 57.1 & 71.4 & 57.1 & 57.1 & 71.4 & 42.9 & 28.6 & 42.9 & 71.4 & 71.4 & 71.4 & 28.6 \\
Enterobacter spp. & 6 & 83.3 & 50.0 & 66.7 & 50.0 & 16.7 & 0 & 16.7 & 50.0 & 66.7 & 66.7 & 16.7 & 16.7 & 33.3 \\
Citrobacter spp. & 5 & 60.0 & 20.0 & 80.0 & 40.0 & 40.0 & 20.0 & 40.0 & 60.0 & 60.0 & 40.0 & 20.0 & 60.0 & 80.0 \\
Providenicia spp. & 3 & 66.7 & 0 & 33.3 & 33.3 & 33.3 & 33.3 & 0 & 33.3 & 66.7 & 33.3 & 33.3 & 66.7 & 100.0 \\
Pseudomonas spp. $(\mathrm{n}=3)$ & 3 & 100.0 & 33.3 & 100.0 & 66.7 & 33.3 & 33.3 & 33.3 & 66.7 & 0 & 66.7 & 33.3 & 33.3 & 66.7 \\
\hline
\end{tabular}

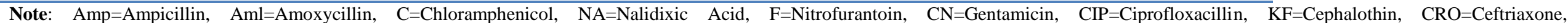

NOR=Norfloxacin, DO=Doxycycline, SXT=Trimethoprim-Sulfamethoxazole, TE=Tetracycline

Table 4: Multiple antimicrobial resistance patterns of bacterial isolates from patients with suspected UTI at St.Paul's Hospital Millennium Medical College, Addis Ababa, Ethiopia, 2013/2014.

\begin{tabular}{|c|c|c|c|c|c|c|c|}
\hline Bacteria & R0 & $\mathrm{R} 1$ & $\mathrm{R} 2$ & R3 & $\mathrm{R} 4$ & $\mathrm{R} 5$ & $\geq \mathrm{R} 6$ \\
\hline E.coli Spp. $(\mathrm{n}=53)$ & $1(1.9)$ & $9(17.0)$ & $18(34.0)$ & $13(24.5)$ & $7(13.2)$ & $2(3.8)$ & $3(5.7)$ \\
\hline Proteus spp. $(\mathrm{n}=8)$ & 0 & $3(37.5)$ & $3(37.5)$ & $1(12.5)$ & 0 & $1(12.5)$ & 0 \\
\hline Klebsiella spp. $(\mathrm{n}=7)$ & $1(14.3)$ & 0 & $3(42.9)$ & 0 & 0 & $2(28.6)$ & $1(14.3)$ \\
\hline Enterobacter spp. $(\mathrm{n}=6)$ & 0 & 0 & 0 & $2(33.3)$ & $1(16.7)$ & $1(16.7)$ & $2(33.3)$ \\
\hline Citrobacter spp. $(\mathrm{n}=5)$ & $1(20.0)$ & $2(40.0)$ & 0 & $1(20.0)$ & 0 & 0 & $1(20.0)$ \\
\hline Providenicia spp. $(\mathrm{n}=3)$ & 0 & $1(33.3)$ & $1(33.3)$ & 0 & $1(33.3)$ & 0 & 0 \\
\hline Pseudomonas spp. $(\mathrm{n}=3)$ & 0 & 0 & $1(33.3)$ & 0 & 0 & 0 & $2(66.7)$ \\
\hline Total isolates $(n=85)$ & $4(4.7)$ & $15(17.6)$ & $26(30.6)$ & $17(20.0)$ & $9(10.6)$ & $6(7.1)$ & $9(10.6)$ \\
\hline
\end{tabular}




\section{DISCUSSION}

E. coli is the commonest uro-pathogen causing complicated and uncomplicated UTI as described previously (5). There are several organisms known to cause UTIs, including $P$. aeruginosa, $S$. saprophyticus, S.epidermidis, Enterococcus spp, P. mirabilis, Klebsiella spp., Citrobacter spp, etc. as reported by earlier workers (17).

The prevalence of bacteriuria in our study $22.4 \%$ was almost similar with what had been previously reported in Gondar (17.8\%) (11), Sudan (19.5 \%) (18), Nigeria $(17.3 \%)$ (19) and Nepal $(21 \%)$ (20). However, this finding is not in agreement with the results from studies done in Addis Ababa Ethiopia (10.9\%) (12), and other parts of the world: India (32\%) (21), Iraq (49.1\%) (22). and Pakistan (51.03\%) (23). The difference in rate of uropathogens in different studies may be explained by differences in methodology used, the environment, social habits of the community, the standard of personal hygiene and education.

In this study, E. coli was by far the most frequently isolated bacterium that occured in $85(20.1 \%)$ of the Gram negative organisms, (55.8\% of all isolates). This is comparable with a finding in Sudan, where E. coli was $42.4 \%$ of the Gram negative isolate (19/9). This also goes with results that obtained in Tanzania where E. coli was $38 \%$ of the Gram-negative isolates and $25 \%$ of all isolate (24). Likewise, many authors have the same findings e.g. in Pakistan and India $(25,26)$.

Given that the majority of therapy for UTIs is empiric and that urinary tract pathogens are demonstrating increasing antimicrobial resistance, continuously updated data on antimicrobial susceptibility patterns is beneficial to guide empiric treatment. The purpose of this study was to describe the susceptibility profiles of isolates of E. coli from patients in St.Paul's Hospital Millennium Medical College, Addis Ababa, Ethiopia. The percentage of isolates of E. coli resistant to ampicillin was found to be as much as 79.2 percent in our set up. Such a high level of resistance to ampicillin has been quoted by many other studies from different parts of the world. For instance, studies in India showed that 80 and 76 percent resistance strains of $E$. coli for ampicillin was observed (27, 28). In Africa (e.g. Sudan, Tanzania, Kenya and Senegal), it has been reported that, $E$. coli in urinary isolates have a high antimicrobial resistance pattern $(18,29,30$, 31). Likewise, other studies have been reported high resistance of $E$. coli towards different antimicrobials was observed in Latin American and Costa Rica $(32,33)$.

The other gram-negative isolates, Proteus spp., in our study showed $62.5 \%$ resistance towards Ampicillin and Amoxicillin, and 96.2\% susceptibility to Trimethoprim-sulphamethoxazole respectively. This is different from the results from Gondar in which $100 \%$ resistance to Ampicillin and Amoxicillin-clavulanicacid and $100 \%$ susceptible to Trimethoprimsulphamethoxazole (11) was reported.

K.pneumoniae showed $85.2 \%$ resistance to Ampicillin. This is more or less similar with studies conducted in Gondar (11), Nigeria (19) and Libya (34).

Multi drug resistance $(\mathrm{MDR}=$ resistance in $\geq 2$ drugs) was observed in $77.6 \%$ of the isolated bacterial uropathogens in this study. This is more or less similar with what had been found in previous findings reported in Ethiopia, Addis Ababa (71.7\%) (12), but higher than a study carried out in Gondar (59.8\%) (11). This indicates that multi drug resistance was found to be very high to the commonly used antibiotics. Antibiotic resistance has been recognized as the consequence of antibiotic use and abuse (35). Therefore, the reasons for this alarming event might be inappropriate and incorrect administration of antimicrobial agents in empiric therapies.

In general, there was a high prevalence of gram-negative bacterial pathogens with high resistance patterns of commonly used antibiotics. However, most isolates were less resistant for Nitrofurantoin, Gentamycin and TrimethoprimSulfamethoxazole. They are considered as appropriate antimicrobials for empirical treatment for urinary tract infections with the absence of culture and sensitivity setting. Increasing antibiotic resistance trends indicate that it is imperative to rationalize the use of antimicrobials in the community and also use these conservatively.

\section{ACKNOWLEDGEMENTS}

The authors are grateful to St.Paul's Hospital Millennium Medical College for the financial and 
facilities support for the study. The study participants also duly acknowledged for voluntarily participating in this project. Additionally, we are indebted to data collectors and supervisors for their cooperation.

\section{REFERENCE}

1. Weichhart T, Haidinger M, Hörl, WH, Säemann MD. Current concepts of molecular defence mechanisms operative during urinary tract infection. Eur J Clin Invest 2008; 38: 2938.

2. Dalela G, Gupta S, Jain DK, Mehta P. Antibiotic resistance pattern in uropathogens at a tertiary care hospital at Jhalawar with special reference to Esbl, Ampc $\beta$-Lactamase and MRSA production. J Clin Diagn Res 2012; 6: 645-651.

3. Kashef N, Djavid GE, Shahbazi S. Antimicrobial susceptibility patterns of community-acquired uropathogens in Tehran, Iran. J Infect Dev Ctries 2010; 4: 202-206.

4. Theodros G. Bacterial pathogens implicated in causing urinary tract infection (UTI) and their antimicrobial susceptibility pattern in Ethiopia. Revista CENIC. Ciencias Biológicas 2010; 41: 1-6.

5. Karlowsky JA, Jones ME, Thornsberry C, Critchley I, Kelly LJ, Sahm DF. Prevalence of anti microbial resistance among urinary tract pathogens isolated from female outpatients across the US in 1999. Int $J$ Antimicrob Agents 2001; 18: 121-7.

6. Warren JV, Abrutyn E, Hebel R, Johnson JR, Schaeffer AJ, Stamm WE. Guidelines for the treatment of uncomplicated acute bacterial cystitis and acute pyelonephritis in women. Clin Infect Dis 1999; 29 : 745-58.

7. Zervos MJ, Hershberger E, Nicolau DP, Ritchie DJ, Blackner LK, Coyle EA, et al. Relationship between fluoroquinolone use and changes in susceptibility to fluoroquinolones of selected pathogens in 10 United States teaching hospitals, 1991-2000. Clin Infect Dis 2003; 37: 1643-8.

8. Nerurkar A, Solanky P, Naik SS. Bacterial pathogens in urinary tract infection and antibiotic susceptibility pattern. J Pharm Biomed Sci 2012; 21: 1-3.
9. de Francesco MA, Giuseppe R, Laura P, Riccardo N, Nino M. Urinary tract infections in Brescia, Italy: Etiology of uropathogens and antimicrobial resistance of common uropathogens. Med SciMonit 2007; 13: 136144.

10. Leegaard TM, Caugant DA, Froholm LO, Hoiby EA. Apparent difference in antimiovrobial susceptibility as a consequence of national guidelines. Clin Microbiol Infect 2000; 6: 290.

11. Yismaw G, Asrat D, Woldeamanuel $\mathrm{Y}$, Unakal C. G. Urinary Tract Infection: Bacterial etiologies, drug resistance profile and associated risk factors in diabetic patients attending Gondar University Hospital, Gondar, Ethiopia. Euro. J. Exp. Bio.2012; 2 (4):889-898,

12. Yeshitela B, Gebre-Selassie S, Feleke Y. Asymptomatic bacteriuria and symptomatic urinary tract infections (UTI) in patients with diabetes mellitus in Tikur Anbessa Specialized University Hospital, Addis Ababa, Ethiopia. Ethiop Med J. 2012; 50 (3): 239-49.

13. Kibret M, \& Abera Bayeh. Prevalence and antibiogram of bacterial isolates from urinary tract infections at Dessie Health Research Laboratory, Ethiopia. Asian Pac J Trop Biomed 2014; 4(2): 164-168.

14. Cheesbourgh M. Medical laboratory manual for tropical countries. 2nd ed. England: Butterworth-Heineman Ltd; 2006.

15. Bauer AW, Kirby WMM, Sherris JC, Turck M. Antibiotic susceptibility testing by standard single disc method. Am J Clin Pathol 1966; 45: 493-496.

16. Clinical and Laboratory Standards Institute (CLSI). Performance Standards for Antimicrobial Disk Susceptibility Tests; Approved Standard-Ninth Edition. Clinical and Laboratory Standards Institute document M2-A9 [ISBN 1-56238-586-0]. CLSI, 940 West Valley Road, Suite 1400, Wayne, Pennsylvania 19087-1898 USA, 2012.

17. Canbaz S, Peksen Y, Tevfik SA, Leblebicioglu H, and Sunbul M. Antibiotic prescribing and urinary tract infection. Int $J$ Antimicrob Agents 2002; 20: 407-11.

18. Hamdan Z. H, Eman K, Amar M. A., Onab S. H, Sarah O. S., Ishag A. Urinary tract infections and antimicrobial sensitivity among 
diabetic patients at Khartoum, Sudan. Annals of Clinical Microbiology and Antimicrobials. 2015; 14 (26): 1-6.

19. Osanyinpeju O. S, Akinleye O. M, Deji A. M, Olaniyan J. T, Akintunde B. G, Buhari O. A. Asymptomatic Urinary Tract Infection In Diabetic Patients In Ago -Iwoye, Ogun State, Nigeria. Journal of American Science. 2014; 10(4s): 72-78.

20. Rabindra S, Mahabouddha, Kathmandu. Urinary tract infection and antibiotic sensitivity pattern among diabetics. Nepal Med Coll J. 2013; 15(1): 1-4.).

21. Chaudhary BL, Charu C, Shukla S. Bacteriology of urinary tract infection and antibiotic susceptibility pattern among diabetic patients. Int. J. Bioassays. 2014; 3 (08): 3224-3227.

22. Al-Qaseer A, Abdul-wahab B. H, Abbas O. K. Bacteriological finding of urinary tract infection in diabetic patients. International Journal Advanced Research. 2014; 2(10): 274-279.

23. Muhammad I, Saeed A, Sohaib M. K, Moeez H, Imtiaz H. B. Urinary tract infection in diabetic patients; causative bacteria and antibiotic sensitivity. J. Med. Sci. 2014; 22 (3): 110-114.

24. Blomberg B, Olsen BE, Hinderaker SG, Langeland N, Gasheka P, Jureen R, Kvale G, and Midtvedt T: Antimicrobial resistance in urinary bacterial isolates from pregnant women in rural Tanzania: implications for republichealth. Scandinavian Journal of Infectious Diseases 2005; 37(4):262-8.

25. Haider G, Zehra N, Munir AA, and Haider A: Risk factors of urinary tract infection in pregnancy. J Pak Med Assoc 2010; 60(3):2136.

26. Mathai E, Thomas RJ, Chandy S, Mathai M, and Bergstrom S: Antimicrobials for the treatment of urinary tract infection in pregnancy: practices in southern India. Pharmacoepidemiol Drug Saf 2004; 13(9):645-52.

27. Mandal J, Srinivas A.N, Buddhapriya D \& Subhash C.P. Antibiotic resistance pattern among common bacterialuropathogens with a special reference to ciprofloxacinresistant
Escherichia coli. Indian J Med Res 2012; (136): 842-849.

28. Gupta N, Kundra S, Sharma A, Gautam V,Arora DR. Antimicrobial susceptibility of uropathogens in India. J Infect Dis Antimicrob Agents 2007; (24): 13-8.

29. Masinde A, Gumodoka B, Kilonzo A, Mshana SE: Prevalence of urinary tract infection among pregnant women at Bugando Medical Centre, Mwanza, Tanzania. Tanzan J Health Res 2009; 11(3):154-9.

30. Sire JM, Nabeth P, Perrier-Gros-Claude JD, Bahsoun I, Siby T, Macondo EA, Gaye-Diallo A, Guyomard S, Seck A, Breurec S, Garin B: Antimicrobial resistance in outpatient Escherichia coli urinary isolates in Dakar, Senegal. J Infect Dev Ctries 2007; 1(3):263-8.

31. Kariuki S, Revathi G, Corkill J, Kiiru J, Mwituria J, Mirza N, Hart CA: Escherichia coli from community-acquired urinary tract infections resistant to fluoroquinolones and extended-spectrum beta-lactams. J Infect Dev Ctries 2007; 1(3):257-62.

32. Gales AC, Sader HS, Jones RN, SENTRY Participants Group (Latin America): Urinary tract infection trends in Latin American hospitals: report from the SENTRY antimicrobial surveillance program (19972000). DiagnMicrobiol Infect Dis 2002; 44(3):289-99.

33. Williams DN, Sannes MR, Eckhoff AA, Peterson PK, Johnson JR, Sannes MR, San Román M, Mora N, Moya J: Antimicrobial resistance in Escherichia coli causing urinary tract infections in Costa Rica: a clinical dilemma. Int $J$ Antimicrob Agents 2003; 21(1):79-81.

34. Ghenghesh KS, Elkateb E, Berbash N, Abdel Nada R, Ahmed SF, Rahouma A, et al. Uropathogens from diabetic patients in Libya: virulence factors and phylogenetic groups of Escherichia coli isolates. J Med Microbiol. 2009; 58: 1006-1014.

35. Albrich WC, Monnet DL, Harbarth S: Antibiotic selection pressure and resistance in Streptococcus pneumoniae and Streptococcus pyogenes. Emerging Infectious Disease 2004; 38:363-371. 